\title{
EL DERECHO A LA INTIMIDAD EN LAS RELACIONES FAMILIARES
}

\author{
Marco Carmona Brenis* \\ Martha Vigil Zárate*
}

Recibido: 01.07.2015

Aprobado: 10.09.2015

\section{RESUMEN}

La filiación es una de las fuentes de parentesco que genera el nacimiento de una serie de relaciones jurídicas entre los progenitores y los hijos, concretizados a través del cumplimiento de una serie de deberes y derechos, como lo señala el Código Civil Peruano, en el ejercicio de la patria potestad, previsto en el Art. 423 del citado cuerpo normativo; sin embargo, puede presentarse que en el ejercicio de esos derechos los padres puedan afectar derechos fundamentales de sus hijos, como es el derecho a la intimidad reconocido en la legislación civil en su Art. 14 y en la Constitución en el Art. 2 Inc. 7, debiendo establecerse la línea de división entre el cumplimiento de los deberes de los padres frente al derecho de los niños/niñas o adolescente y el respeto de su vida privada, considerando su edad, las circunstancias y el interés superior del niño.

Del mismo modo, en las relaciones conyugales se puede presentar esta problemática, al contraponerse los deberes que se deben recíprocamente los cónyuges, como el de fidelidad y cohabitación, con derechos fundamentales de estos, por lo que es necesario también delimitar su ejercicio.

\section{ABSTRACT}

The affiliation is a source of relationship that generates the birth of a series of legal relations between parents and children, concretized through the implementation of a series of rights and duties, as noted by the Peruvian Civil Code, in the exercise of parental rights provided for in Art. 423 of that legislative body; but may occur in the exercise of these rights the parents can affect their children's fundamental rights, such as the right to privacy recognized in civil law in Art. 14 and the Constitution in Art. 2 Inc. 7, having the dividing line between fulfilling the duties of parents against the rights of children / girls or adolescent and respect for his privacy established, considering his age, the circumstances and interests of the child.

Similarly, in conjugal relations can be presented this problem to be weighed against the duties that are mutually must spouses, such as loyalty and cohabitation, which may be contrasted with fundamental rights of these, so it is also necessary to define its exercise.

\section{PALABRAS CLAVE}

Relaciones familiares. Intimidad.

\section{KEY WORDS}

Family relationships. Privacy.

* Abogado y Doctor en Derecho por la Universidad César Vallejo. Estudios de Máster en Bioética por la Universidad Europea Continental España. Segunda Especialidad en Derecho de Familia por la Universidad Señor de Sipán. Docente de Derecho de Personas, Derecho Genético, Derecho de Familia y Sucesiones de la Universidad Señor de Sipán y Universidad César Vallejo. Miembro del Instituto Peruano de Derecho Civil. Miembro de la Asociación Latinoamericana de Niñez, Adolescencia y Familia, de Mendoza -Argentina.

** Abogada, por la Universidad de Sipán. Maestría en Derecho Procesal y Doctora en Derecho por la Universidad César Vallejo. Docente de la Universidad César Vallejo - Piura. Ex Especialista Judicial de la Corte Superior de Justicia de Piura. 


\section{INTRODUCCCIÓN}

El derecho a la intimidad tiene su reconocimiento en el texto constitucional, en su artículo $2^{\circ}$; en los tratados internacionales, como es el caso de la Declaración Universal de los Derechos del Hombre y en la Convención de los Derechos del Niño y, en nuestra normatividad civil, en su artículo $14^{\circ}$.

El derecho a la intimidad, desde el punto de vista normativo, no ha evolucionado; sin embargo, en los últimos años, las relaciones intersubjetivas en las que se protege dicho derecho a la intimidad han cambiado sustancialmente las relaciones en las cuales se sustenta el derecho a la intimidad, y, de manera muy especial, en las relaciones familiares, lo que debe de conllevar a establecer nuevas ideas respecto al derecho a la intimidad, estableciendo reglas o principios que implican una debida protección de este derecho fundamental.

En nuestra legislación, podemos decir que existen dos dimensiones de la intimidad, las que a su vez son complementarias: la personal y la familiar. Partimos del trato que le da a este derecho la ley de leyes; es decir, la Constitución Política del Perú vigente.

Así, el artículo $2^{\circ}$ establece en su inciso 7 que toda persona tiene derecho "a la intimidad personal y familiar".

De igual manera, el Código Civil vigente, en su artículo $14^{\circ}$ establece el respeto a la intimidad de la vida personal y familiar. Y, por último, se refiere a este derecho el Art. 54 del
Código Penal: "El que viola la intimidad de la vida personal o familiar...", y el Art. 156: "El que revela aspectos de la intimidad personal y familiar...".

El presente artículo trata de explicar los ámbitos en donde se desarrolla el derecho a la intimidad en la vida familiar, es decir, el respeto de este derecho que se deben los miembros de las familias, como es el caso del que nace del ejercicio de la patria potestad, es decir, de los padres respecto de los hijos (relaciones paterno filiales); así como las consecuencias jurídicas que conllevaría su vulneración, para lo cual se hará un análisis de sus contenidos y distintas formas de tratamiento que se viene dando en la jurisprudencia nacional y comparada.

\section{El Derecho a la Intimidad: DEFINICIÓN}

En 1981, los juristas norteamericanos Samuel D Warren y Louis D. Branders plantearon prolijamente el tema del derecho a la intimidad (righth to privacy) en la revista de Derecho de la Universidad de Harvard. En 1963, se produce en el estado de Colorado el caso Dayly Times Democrat vs. Graham, el cual se generó a raíz que una joven fue fotografiada en un parque de diversiones justo cuando una corriente de aire levantó su vestido. La justicia señaló que, aún en lugares públicos, existen cosas que, aunque estén a la vista, siguen siendo privadas.

El ejercicio del derecho a la intimidad conlleva los dos aspectos siguientes: a) Preservación del no conocimiento ajeno de ciertos aspectos o manifestaciones de la vida privada (personal y familiar).

b) Establecimiento jurídico de una suerte de distancia o discreción por parte de terceros, a efectos de no atentar contra los sentimientos 0 costumbres personales o familiares (García Toma, 2013, págs. 325-328)

En sentencia, el Tribunal Constitucional español, mediante STC $127 / 2003$, de 30 de junio de 2003, define el derecho a la intimidad como:

“un derecho al secreto, a
ser desconocido, a que los
demás no sepan qué somos
o lo que hacemos, vedando
que terceros, sean particu-
lares o poderes públicos,
decidan cuales sean los
lindes de nuestra vida pri-
vada pudiendo a cada per-
sona reservarse un espacio
resguardado de curiosidad
ajena, sea cual sea lo con-
tenido en ese espacio". (De
Verda y Beamonte, 2012,
pág. 165)

Por su parte, Fermenía López señala que:

"El reconocimiento a la intimidad significa, (...) admitir un campo de actuación a la autonomía privada en orden de fijación de datos y circunstancias que determinan ese "ámbito propio y reservado frente a la acción y conocimiento de los demás", necesario "para mantener una calidad mínima de la vida humana. 
En consecuencia, se admite que el derecho a la intimidad posee un doble aspecto, positivo y negativo. En su aspecto positivo, significa que el individuo dispone de un poder jurídico sobre la publicidad de la información relativa al círculo reservado de su persona y su familia"; y en su aspecto negativo, supone, el poder de resguardar ese ámbito reservado frente a la divulgación del mismo por terceros $y$ frente $a$ una publicidad no querida" (Fermenía López, 2012, pág. 199).

El Diccionario de la Real Academia define a la intimidad como la "zona espiritual íntima y reservada de una persona o de un grupo, especialmente de una familia". No obstante, parece haber consenso en afirmar que "íntimo" es aquello reservado de cada persona.

Por lo tanto, el derecho a la intimidad puede definirse como el "poder concedido a la persona sobre el conjunto de circunstancias personales que puede excluir ilícitamente del conocimiento de terceros".

Para Ramón De Verda, en el derecho a la intimidad, en la vida privada, hay datos que los demás no tienen por qué conocer, pero que, objetivamente, no parece que puedan ser considerados como parte de ese "reducto de inmunidad", sin cuya preservación (con el que la jurisprudencia constitucional identifica la intimidad) "no es realizable ni concebible siquiera, la existencia en dignidad". Seria, por ejemplo, el caso del importe de la nómina mensual o de los datos bancarios. Asimismo, agrega que la intimidad protege la esfera en que se desarrollan las facetas más singularmente reservadas de la vida de la persona - el domicilio donde realiza su vida cotidiana, las comunicaciones en las que expresa sus sentimientos, por ejemplo -, la privacidad constituye un conjunto, más amplio, más global, de facetas de su personalidad. (De Verda y Beamonte, 2012, págs. 165-166)

En relación con el derecho a la intimidad, el Tribunal Constitucional español ha reiterado que se funda en la necesidad de garantizar «la existencia de un ámbito propio y reservado frente a la acción y conocimiento de los demás, necesario, según las pautas de nuestra cultura, para mantener una calidad mínima de la vida humana, que puede ceder ante la prevalencia de otros derechos, como el derecho a la información cuando se refiera a hechos con relevancia pública, en el sentido de noticiables, y a que dicha información sea veraz» (STC 77/2009, de 23 de marzo, FJ 2).

\section{Contenido del derecho a la INTIMIDAD}

El derecho a la intimidad ha sido ampliamente desarrollado por la doctrina nacional y extranjera; para Marcela M. Leloir y Agustín Sojo, este derecho comprende tres grandes grupos de derechos o deberes: a) Los que se refieren al derecho a ser dejado solo o gozar de la tranquilidad; b) la autonomía de las decisiones o autodeterminación, y c) el control de la información personal.
(Leloir, Marcela y Sojo, Agustín, 2011, pág. 94)

Para nuestro Tribunal Constitucional, el contenido esencial del derecho a la intimidad personal, reconocido por el art. 2 Inc. 7 de la Constitución, hace alusión a aquel ámbito protegido del derecho, cuya develación pública implica un grado de excesiva e irreparable aflicción psicológica en el individuo, lo que difícilmente puede predicarse en torno al componente económico del derecho" (STC 00011-2004-Al,FJ37). (Landa Arroyo, 2010, pág. 28)

Ahora bien, cabe señalar la distinción entre los derechos a la intimidad personal y familiar, respecto al derecho a la privacidad. Al respecto, el Tribunal Constitucional señala que: "Mediante la autodeterminación informativa se busca proteger a la persona en sí mismo, no únicamente en los derechos que conciernen a su esfera personalísima, sino a la persona en la totalidad de ámbitos; por tanto no puede identificarse con el derecho a la intimidad personal y familiar, ya que mientras éste protege el derecho a la vida privada, el derecho a la autodeterminación informativa busca garantizar la facultad de todo individuo a poder preservarlo ejerciendo un control en el registro, uso y revelación de datos que le conciernen (...)" (Landa Arroyo, 2010, págs. 117-118).

Asimismo, en otra sentencia, el TC, en el caso Magaly Medina Vela señala que: "La vida privada es un derecho fundamental en primordial relación 
con la intimidad. El último de ellos tiene una protección superlativa dado que configura un elemento infranqueable de la existencia de la persona; la vida privada, por su parte, la engloba y también incluye un ámbito en donde se admiten algunas intervenciones que habrán de ser consideradas como legítimas, vinculándose inclusive con otros derechos como la inviolabilidad de domicilio (...)" (Exp. $\mathrm{N}^{\circ}$ 067712-2005-HC/TC).

Por tanto, coincidimos con Víctor García al señalar que, respecto a estos dos derechos, puede deducirse lo siguiente (García Toma, 2013, pág. 333):

a) El inciso 7 del Art. 2 de la Constitución engloba tanto el derecho a la vida privada como el derecho a la intimidad

b) El derecho a la intimidad tiene una protección mayor que el derecho a la vida privada.

\section{EL DERECHO A LA INTIMIDAD EN LAS RELACIONES FAMILIARES}

El derecho a la intimidad cobra una vital importancia en la vida familiar, que nace como consecuencia del ejercicio de los derechos subjetivos familiares que dan lugar a una serie de relaciones jurídicas de orden familiar, como es en la relación paterno filial y la relación conyugal u otras relaciones similares.

Siguiendo en la idea de Marcela M. Leloir y Agustín Sojo, el derecho a la intimidad en las relaciones familiares comprende el llamado "Derecho a la tranquilidad", en el cual se puede presentar una serie de problemáticas en su ejercicio. Así, los autores señalan que "En el caso de las relaciones familiares (conyugales o paterno filiales), este derecho puede entrar en tensión con otros derechos de mayor jerarquía, tal como el derecho del niño a tener una adecuada comunicación con su padre, así como el derecho de la madre a que su ex pareja no la perturbe se contrapone con el derecho del niño y su padre a mantener trato habitual. En este último caso, se debe de compatibilizar el derecho a la intimidad y comunicación paterno filial" (Leloir, Marcela y Sojo, Agustín, 2011, pág. 96).

En el derecho de familia, este derecho a ser dejado solo se contrapone, en cierta medida, con los deberes familiares. Así, en el deber de cohabitación entre los cónyuges, exige que marido y mujer no se dejen solos el uno al otro. Si bien el deber de asistencia conyugal comprende el deber de acompañar al otro, ello no significa que los esposos deben de estar siempre juntos, y se admite cierta distancia entre ellos.

\subsection{EL DERECHO A LA INTIMI- DAD FAMILIAR EN LAS RELA- CIONES PATERNO-FILIALES}

En las relaciones paterno-filiales, el derecho a ser dejado solo aparece coartado por ciertos deberes familiares, pero no por ello deja de existir. Un hijo aun si fuese menor de edad, tiene derecho a que se respeten sus espacios privados, pero al mismo tiempo un padre no puede desentenderse de su hijo, por cuanto tie- ne deberes de cuidado que le exigen ser parte de su vida. En ese sentido, el padre que tiene sospechas razonables de que su hija o hijo puede ser víctima de cierta conducta delictiva tiene derecho a entrometerse en su esfera más íntima de correspondencia electrónica, para velar por los intereses del menor, pero no por simple curiosidad.

Del mismo modo, tiene el derecho a revisar lo que sus hijos realizan a través de las redes sociales, porque existe un deber de vigilancia que obliga a los padres a responder por las injurias que sus hijos puedan divulgar a través del internet.

\subsubsection{LA TITULARIDAD DEL DE- RECHO A LA INTIMIDAD POR LOS MENORES}

La Convención Internacional sobre los Derechos del Niño establece en su Art. 16 que: "Ningún niño será objeto de injerencias arbitrarias o ilegales en su vida privada, su familia, su domicilio o su correspondencia, y de ataques ilegales a su honor y a su reputación"

Asimismo, la Carta Europea de Derechos del Niño en su Art. 8.29 declara: "todo niño tiene derecho a no ser objeto por parte de un tercero de intrusiones injustificadas en su vida privada, en la de su familia, ni sufrir atentados ilegales contra su honor".

Como se señala, existe un reconocimiento expreso de los derechos fundamentales de los menores de edad. Sin embargo, pueden presentarse situaciones en donde se enfrentaría este derecho frente al ejer- 
cicio de la patria potestad de los padres.

Al respecto, en "el ordenamiento italiano se considera la posibilidad de injerencia de los padres en el ámbito privado de los hijos (...) y afectaría a aquellos menores cuyas condiciones de madurez no fueran suficientes, ya que se parte del reconocimiento de un ámbito de intimidad de los hijos menores que no pueden ser lícitamente invadido por los padres".

Para la doctrina italiana, el derecho a la intimidad del menor aparece justificado en términos generales, como un derecho de la personalidad del cual no puede ser privado, pero también como un deber especifico de los padres en el desarrollo de la función educativa que afecta fundamentalmente a aquellos menores cuyas condiciones de madurez no son suficientes, obligando a los padres a vigilar su formación y planteando, a la vez, el problema de la legitimidad del control y de su extensión.

En Francia, la jurisprudencia de la Corte de Casación entiende que no es suficiente con el consentimiento del menor para la divulgación de hechos relativos a su vida privada si quienes detentan la autoridad no han consentido dicha divulgación.

Las condiciones de madurez y suficiente juicio conforman, por tanto, el criterio delimitador de la actuación de los representantes legales en la esfera de los derechos de la personalidad del menor" (Fermenía López, 2012, págs. 208-209).

\subsubsection{LA TOMA DE DECISIONES PERSONALES}

La autonomía siempre se ve limitada por las nociones de orden público y los derechos de terceros. Sin embargo, el orden público debe ceder espacio a la autonomía personal

Existen cuestiones de autonomía en toma de decisiones que vienen transformando las relaciones de familia. Por un lado, la incorporación de la capacidad progresiva del menor de edad y, por otro lado, el reconocimiento de cierta autonomía a favor de las personas con discapacidad, transforma las relaciones familiares. En el primer caso, se presentan dos situaciones: el derecho de los padres a tomar decisiones por los hijos que no han desarrollado aun su propio juicio; y el derecho de las personas menores de edad a tomar sus propias decisiones.

Así, por ejemplo, un tribunal argentino no reconoció el derecho de los padres a decidir por su hijo y rechazar el plan nacional de vacunación; resolvió que si bien los padres tenían el derecho de decidir por sus hijos, debía imponerse este plan, por cuanto de lo contrario podría afectarse en juego derechos de terceros que podrían contagiarse de enfermedades y, por supuesto, el derecho a la salud del niño, debiéndose tener siempre presente el punto de vista del mejor interés del niño.

Pero, cuando el niño alcanza la adolescencia y comienza a desarrollar su propio juicio, ello trae dificultades para determinar a partir de cuándo va a poder tomar sus propias decisiones, sin necesidad de acudir a sus padres

Al respecto, en el derecho internacional se tiende a adoptar el sistema de capacidad progresiva como nuevo paradigma. Por tanto, para este sistema, los niños pueden tomar sus propias decisiones en todas aquellas cuestiones que no hagan a su salud o pongan en riesgo su crecimiento; pero en la mayoría hacen prevalecer el interés superior del niño por sobre su autonomía en aquellas cuestiones fundamentales.

Sin embargo, también se deja a la judicatura facultades tan amplias que permiten replantearse la existencia de un derecho a la vida privada y familiar. Tal es el caso en Inglaterra, en donde se falla invocando la idea de que los menores de 16 años son autónomos para elegir y decidir sus propias prácticas médicas (control de natalidad o práctica anticonceptiva).

De lo que se trata es que las personas menores tengan la posibilidad de forjar su propio destino, pero ello no significa que las personas que los rodean no puedan influenciarlas o acompañarlas en sus decisiones, mas sin decidir por ellas.

\subsection{EL DERECHO A LA INTIMI- DAD FAMILIAR EN LAS RELA- CIONES CONYUGALES}

Sobre los deberes conyugales, Azpiri (Leloir, Marcela y Sojo, Agustín, 2011, pág. 98) señala que existe entre ellos un deber mutuo que impone a la pareja la obligación de mante- 
ner reserva de las cuestiones intimas de la relación y que este deber perdura luego de disuelto el matrimonio. Al respecto, en un caso de divorcio en Argentina, existen tribunales que han considerado restringir el considerar las grabaciones telefónicas acompañadas por el marido como prueba del adulterio de su mujer, aparte de que ella había solicitado que se le prohibiera al marido difundir las grabaciones entre familiares, amigos y cualquier tercero.

Asimismo, existen ciertos actos que se consideran injurias graves como, por ejemplo, grabar conversaciones telefónicas ajenas; el ocultar una filmadora para exponer la vida diaria del hogar en prueba de algún maltrato; espiar a otro, y peor aún, comentárselo a otro aunque sea abogado o juez por no ser compatible con los deberes matrimoniales.

El Tribunal Constitucio-
nal Peruano considera al
respecto que,

"La relación íntima entre hombre y mujer es un derecho natural inherente a la naturaleza humana (...) que tiene relación directa con la libertad del hombre individual y socialmente, en el primer caso, está íntimamente relacionado con su normal desarrollo sicofísico y su bienestar espiritual, y en el segundo caso con su desenvolvimiento familiar y social". (Exp. $N^{\circ}$ 015752007-PHC/TC)

Pedro Fermenía López señala que "en sentencia española, se condenó a un año de prisión y cinco de alejamiento de su ex mujer y de sus dos hijas por instalar una cámara de video doméstica en el baño de la vivienda familiar al sospechar que una de sus hijas sufrían de anorexia y se provocaba vómitos, lo que no admitía. Sin embargo, la cámara grabó no solo a la hija que aparentemente sufría el trastorno alimentario, sino que también tomó imágenes de su mujer, de la que estaba separado, de su otra hija, incluso de amigas de estas. El fallo también impone una indemnización a su ex mujer y a cada una de sus hijas por daños morales causados. La hija, no obstante tuvo que ser sometida a tratamiento por bulimia" (Fermenía López, 2012, pág. 196).

En otra sentencia del TC español, se condenó a prisión de un año al marido que había intervenido la línea telefónica del entonces domicilio conyugal y grabado conversaciones intimas de su mujer, que luego difundió entre la tía de la víctima y dos de sus amigas para desprestigiarla. De igual manera, en otro caso se condenó al pago de una indemnización de 9,000 euros a una suegra, que había manifestado su sospecha de que el hijo de su nuera no era de su marido, sino de un empleado de aquélla por tratarse de un dato perteneciente al ámbito íntimo de la pareja y, en su caso, del hijo, por lo que, aunque fuera verdad, no podía ser divulgado. (De Verda y Beamonte, 2012, págs. 180-181)

José De Verda aduce, con respecto a la difusión no consentida de imágenes de desnudos voluntariamente captados, que la captación o difusión de imágenes de desnudos del otro cónyuge (relación conyugal u otra análoga), sin su consentimiento, constituye una intromisión en su derecho a la intimidad en su dimensión corporal. Es evidente la afectación del derecho a la intimidad y a la propia imagen de la víctima, pues el consentimiento para captar una imagen no significa, necesariamente, autorización para difundirla, ya que el consentimiento debe ser expreso para cada concreto acto de intromisión (captar y difundir imágenes son conductas diversas). Así, por ejemplo, en un tribunal español se condenó a un año de prisión y a pagar a su mujer 6000 euros en concepto de daño moral, al marido que puso al alcance de la página de internet -denominada sex casero.com, bajo el título "Paula la golfa de Oviedo"-, tres fotografías de la denunciante, sin su permiso, en dos de las cuales aparecía con los pechos descubiertos y en una tercera sin ropa. (...). Es evidente que sobre cada cónyuge pesa la prohibición de divulgar entre terceros aspectos de la vida íntima del otro, de los que tenga conocimiento por razón de la convivencia o de la relación de confianza que se establece entre los cónyuges, así como de los que afecte la vida íntima de la familia. Este derecho persiste después de la disolución del matrimonio. Asimismo, agrega, que en el origen del proceso se halla la publicación de un libro titulado "Hasta la libertad", en el que el autor, en clave autobiográfica, narraba sus experiencias vitales y su personal visión de la situación carcelaria española. En algunas de sus páginas 
se contenían referencias a la demandante, desde su primera toma de contacto hasta su ruptura, pasando por su matrimonio. La Audiencia consideró probado que en el libro se revelaron detalles de la vida privada de la demandante que constituye atentado a su intimidad; se descubrieron aspectos de su salud; se divulgó el contenido en las cartas y se narraron encuentros íntimos de ambos (De Verda y Beamonte, 2012, págs. 190-192).

Por último, la jurisprudencia española (STC de 17 de junio del 2009) ha considerado, por ejemplo, una intromisión ilegítima en el derecho a la intimidad familiar el que un medio de comunicación revelara la filiación biológica de un menor y el hecho de ser su madre natural una prostituta o atribuyera a un padre una conducta infiel y una adicción al sexo. (...). La familia es el cauce al servicio del libre desarrollo de la personalidad de los seres humanos, lo que presupone garantizar en su seno la efectividad de los derechos fundamentales $y$, entre ellos, el derecho a la intimidad de sus componentes (De Verda y Beamonte, 2012, pág. 179).

\subsection{El DERECHO A LA INTIMI- DAD Y LAS REDES SOCIALES}

Las redes sociales on line, han transformado el concepto de intimidad y su aplicación en la esfera familiar. Pero, además, la generalización del uso de dispositivos móviles por medio de los cuales se puede captar la imagen y el sonido permite ámbitos de injerencia que en otro tiempo resultaban imposibles. Así, por ejemplo, inva- de la intimidad de los menores que sus padres coloquen dispositivos que capten la imagen o el sonido en espacios reservados a la vida privada; salvo que sea para prevenir la lesión o atentado contra algún otro derecho fundamental del menor (Fermenía López, 2012, pág. 196).

Por tanto, adquiere especial trascendencia el uso de las "redes sociales" por parte de los menores, lo cual ha producido un cambio al concepto de intimidad, dado que deja de ser una esfera sustraída al conocimiento de los demás, para convertirse en un perfil donde los sujetos exteriorizan de forma voluntaria su "personalidad" y facilitan datos personales para construir lo que se denomina "Extimidad", planteando inseguridades para la intimidad de los sujetos, así como terceras personas, ya que los datos a las mismas son accesibles de forma pública y global para millones de usuarios. Así, estudios recientes demuestran que el $71 \%$ de los escolares con edades entre 10 y 18 años tiene uno o varios perfiles en las redes sociales. A partir de los 14 años, el porcentaje supera el $80 \%$ y alcanza mayor índice de uso; el $85 \%$ justo antes de la mayoría de edad.

Debe tenerse en cuenta, no obstante (...) que se parte del principio de no imponer a los prestadores de servicios la obligación de controlar o supervisar todos los contenidos que se trasmiten o se almacenan, lo cual sería además imposible. Sin embargo, se les impone el deber de evitar la omisión de delitos o activida- des ilícitas en la red en cuanto tomen conocimiento de ellas, retirando e imposibilitando, con la diligencia debida, el acceso de aquella información que sea así calificada.

Desde este punto de vista, la labor de colaboración de los padres en el control de los perfiles de sus hijos menores resulta fundamental.

Por último, la intervención de los padres también estaría justificada en base a la lesión de sus propios derechos personales, cuando la intervención del menor, con suficiente juicio, en las redes sociales, no afectase únicamente a su esfera privada sino también a la "intimidad familiar" o a la intimidad personal de algún otro de los miembros integrantes de la familia (Fermenía López, 2012).

\section{ConClusión}

Como se ha expuesto, podemos concluir que el derecho a la intimidad en las relaciones de orden familiar, demanda una especial protección, más aún cuando se contraponen dos derechos fundamentales, por lo que los tribunales deberán de ponderar los mismos y preferir el derecho que menos se vulnere.

En el caso de las relaciones paterno filiales, frente al derecho de los padres en el ejercicio de la patria potestad - responsabilidad parental, debe de primar el principio del interés superior del niño, pero siempre y cuando no se vean afectados derechos fundamentales del menor. 
En las relaciones conyugales, existe una mayor protección y sanción en la publicación de la información de la vida íntima de la pareja, en donde inclusive el ejercicio regular de un derecho no siempre legitima a una persona a ventilar la vida íntima de la misma. Asimismo, cualquier información en donde exista datos de la vida íntima, aunque fuese hecha con el consentimiento de la pareja, antes de ser revelada, deberá de contar nuevamente con el consentimiento de esta; caso contrario, su difusión vulneraría tal derecho y debe ser materia de sanción tanto en el ámbito penal como en lo civil a través del resarcimiento.

Debemos dejar en claro que la institución de la familia ha sufrido cambio en su concepción; es decir, en que contem- poráneamente debe ser concebida ya no como una constitución, sino como un medio o instrumento de desarrollo del individuo, por lo que se debe priorizar el respecto de sus derechos fundamentales, frente al ejercicio de los derechos subjetivos familiares de sus miembros.

\section{REFERENCIAS BIBLIOGRÁFICAS}

De Verda y Beamonte, José (2012). "Resarcimiento de daño moral por intromisión ilegítima en la intimidad del otro cónyuge". En: Moreno Martínez, Juan (Coordinador). La Responsabilidad Civil en las Relaciones Familiares. Madrid: Dykinson S.L.

Fermenía López, Pedro (2012). “Daños por violación en las relaciones paterno filiales". En: Moreno Martínez, Juan (Coordinador). La Responsabilidad Civil en las Relaciones Familiares. Madrid: Dykinson.

García Toma Víctor (2013). Derechos Fundamentales. $2^{a}$. edición. Lima: Editorial ADRUS.

Landa Arroyo, César (2010). Los Derechos Fundamentales en la jurisprudencia del Tribunal Constitucional. Lima: Editorial Palestra.

Leloir, Marcela \& Sojo, Agustín Sojo (2011). "La intimidad que se deben los familiares actualmente". En: Derecho de Familia: Revista interdisciplinaria de doctrina y jurisprudencia. Buenos Aires: Abeledo Perrot. 